\title{
CORRESPONDENCE
}

Letters of 600 or less, with minimal allowance for tables, figures, and references, will be considered for publication. Rules regarding prior publication, conflict of interest, etc., are the same as for full manuscripts. All letters are subject to editing and condensation. Proofs will not be distributed.

\section{NMR Chemistry of Red Blood Cell Constituents}

To the Editor:

Additional comments and corrections need to be made to our paper published in this journal (Domino et al. 1985). The key metabolite in red blond cells is 2,3-diphosphoglycerate and not 2,3 diphosphoglycerol, as stated in our paper. Currently 2,3-bisphosphogylcerate is a more acceptable term for this key metabolite in red blood cells. As noted in our paper, the levels of 2,3-bisphosphogylcerate do not change as a result of chronic lithium therapy.

An additional comment is necessary regarding the order of priorities in citing the literature. It should be noted that ours was not the first nuclcar magnetic resonance (NMR) study on this subject. Johnson and Kuchel (1980) reported that in 51 blood samples of patients treated with lithium, there was a correlation coefficient of -0.24 between serum lithium and red blood cell choline. Furthermore, red blood cells from patients not treated with lithium showed only a minute choline resonance in the NMR spectrum. This early work was followed by a more detailed NMR study by Jones and Kuchel (1980), who showed a dramatic increase in red blood cell choline in lithium-treated patients. Jones and Kuchel (1980) also assigned choline to be adjacent to the peak labeled "u4" in the NMR paper by Brown et al. (1977), which was previously "unassigned, but coincident with quaternary amine methyls of acetylcholine"; $u 4$ is now known to be ergothioneine (e.g., Kuchel 1981). What we reported as their error in assignment was not a true error, but rather they noted that the peaks for choline and acetylcholine were almost, but not quite, coincidental. It is well known that red blood cells contain acetylcholinesterase and that any acetylcholine present would be rapidly hydrolyzed to choline. Although the contribution of acetylcholine to the choline NMR peak of human red blood cells is certainly negligible, there is evidence that minute amounts of acetylcholine do exist in human red blood cells (see Hanin et al. 1978). This latter finding still poses a mystery that needs to be solved.
During the period our paper was being submitted for review and publication in this journal, Kuchel et al. (1984) reported an extensive study on the determination of red blood cell choline and ergothionine levels in bipolar patients on lithium maintenance therapy. After 4 weeks of lithium treatment, red blood cell choline levels increased sixfold, whereas ergothionine levels did not change. The increased choline levels were unrelated to clinical state and did not distinguish lithium responders from nonresponders. Their findings are in agreement with our current opinion that a potential clinical caveat in measuring red blood cell choline in patients is an index of recent lithium ingestion if a clinical history is unattainable or unreliable.

Perhaps the most important question is why does red blood cell choline increase so dramatically in lithium-treated patients. Jenden et al. (1980) proposed that the choline came from the hydrolysis of intracellular phospholipids. Crucial to this proposal was evidence by Chapman et al. (1982) that $\mathrm{Ca}^{2+}$. dependent phospholipase-D activity is present in human red blood cells. Beilharz et al. (1986) have recently conducted an experimental study and a computer simulation of the turnover of choline in red blood cells of patients treated with lithium. Their published answer to this important question involves several steps. (1) Plasma phosphatidylcholine, associated with high-density lipoproteins, exchanges with the phospholipids in the red blood cell membrane. (2) Phosphatidylcholine in the outer membrane undergoes two-dimensional translation and rotation and flips between the outer to the inner layer of the bilayer. (3) Inner membrane layer phosphatidylcholine is now exposed to intracellular phospholipase D. (4) The latter enzyme splits off choline intracellularly. (5) Free intracellular choline can also come from a membrane choline transport system, which can transport free choline from the plasma into the red blood cell and vice versa. (6) The entire system at equilibrium provides a steady-state intracellular red blood cell choline level. (7) Choline transport (influx as well as efflux) is inhibited by lithium treatment. (8) Thus, over time, red blood cell choline accu- 
mulates to a new steady-state level in the lithiumtreated patient.

Perhaps the most important question is whether patients treated with lithium show a comparable increase in their brain choline, as is true in their red blood cells. We need to know how lithium exerts its remarkable therapeutic effects. Newer techniques, such as positron emission tomography (PET) and NMR imaging, will hopefully help provide some useful data on human brain choline levels that may lead to an answer.

Department of Pharmacology

\section{E. F. Domino}

University of Michigan

Ann Arbor, MI 48109-0010

\section{References}

Beilharz GR, Middlehurst CR, Kuchel PW, Hunt GE, Johnson GFS (1986): An experimental study and computer simulation of the turnover of choline in the erythrocytes of patients treated with lithium carbonate. Aust J Exp Biol Med Sci 64:271-289.
Chapman BE, Beilharz GR, York MJ, Kuchel PW (1982): Endogenous phospholipase and choline release in human erythrocytes: A study using ${ }^{1} \mathbf{H}$ NMR spectroscopy. Biochem Biophys Res Commun 105:1280-1287.

Domino EF, Sharp RR, Lipper S, Ballast CL, Delidow B, Bronzo MR (1985): NMR chemistry analysis of red blood cell constituents in normal subjects and lithium-treated psychiatric patients. Biol Psychiatry 20:1277-1283.

Hanin I, Kopp U, Zahniser NR, Shih TM, Spiker DG, Merikangas JR, Kupfer DJ, Foster FG (1978): In Jenden DJ (ed), Advances in Behavioral Biology 24: Cholinergic Mechanisms and Psychopharmacology. New York: Plenum, pp 181-195.

Johnson G, Kuchel PW (1980): To the editor: Redcell choline in manic-depressive patients taking lithium. $N$ Engl $J$ Med 303:705.

Kuchel PW (1981): Nuclear magnetic resonance of biological samples. CRC Rev Anal Chem 12:155-231.

Kuchel PW, Hunt GE, Johnson GFS, Beilharz GR, Champan BE, Jones AJ, Singh BS (1984): Lithium, red blood cell choline and clinical state. A prospective study in manic-depressive patients. $J$ Affect Dis 6:83-94. 